\title{
UNUSUAL CASES OF HERPES ZOSTER, INCLUDING SIMULTANEOUS UNILATERAL SUPRA-ORBITAL AND THORACIC ERUPTION
}

\author{
EDWARD FOULKE CORSON, M.D. \\ AND \\ FRANK CROZER KNOWLES, M.D. \\ PHILADELPHIA
}

In clegree of frequency, herpes zoster has been noted to occur in a proportion ranging between 1 and 2 per cent. of all diseases of the skin. Usually the figure is near the smaller percentage and is fairly constant in both Európean and American clinics. The patches of inflammatory redness, bearing tense, deeply situated vesicles, scattered along the area of distribution of a peripheral nerve, are familiar to the average practitioner and form an easily recognized dermatologic entity. It is ascribed to several causes, some of them with strong claims to recognition. It has several varieties, distinguished mainly by the severity of the disease and the region attacked. During certain periods it has been noted frequently, amounting almost to an epidemic; at other times it has been observed seldom, and sporadically. While clinically one of the clearest-cut dermatoses, atypical cases are occasionally encountered, whose vagaries may have some significance and whose variations, when recorded, may prove of use in advancing our knowledge of the disease.

Certain points of interest in this disease continue to be discussed: the relationship of the disease to varicella; the significance of the rarely observed generalized eruption accompanying a frank zoster; the paralysis exceptionally seen to coexist with the outbreak; the seldom observed bilateral efflorescence at the same or different levels; and, as in one of the cases we present, the presence of the disease simultaneously on the same side in widely separated locations.

Cases exhibiting eruptions in the distribution of two, and even three, adjacent nerve roots on the same side are not uncommonly noted. More unusual are those cases in which definite and wide separation exists between areas involved on the same side with only spinal nerves affected. Little's ${ }^{1}$ patient had outbreaks corresponding to the third and eighth thoracic segments on one side, with the intervening roots apparently unaffected. Likewise, few instances have been observed in which cranial and spinal nerves were affected at widely distant points. The cases reported were nearly equally divided between unilateral distribution and bilateral, in which the cranial nerve involved was on

1. Little, E. G. G.: Proc. Royal Soc. Med. 8:130, 1914-1915. 
the opposite side from that of the spinal nerve affected. Mobley's ${ }^{2}$ case of bilateral herpes zoster in a woman, aged 66, showed simultaneous involvement of the left facial region and neck, with a thoracic outbreak following the course of the seventh right intercostal nerve. Hutchinson ${ }^{3}$ reported frontal and dorsal zoster coexisting on different sides of the body. Barber ${ }^{4}$ could find no instance similar to his case in which frontal and seventh dorsal herpes zoster simultaneously erupted on the left side. Cooper Perry was unable to recall having seen a like distribution, and Adamson, in 1914, said he had not previously heard of two separate areas being affected on the same side at the same time. Bradshaw, ${ }^{5}$ however, had reported just such a case as Barber's twenty-five years earlier. Nevertheless, our case, being one of a type apparently quite limited in numbers, is reported without apology.
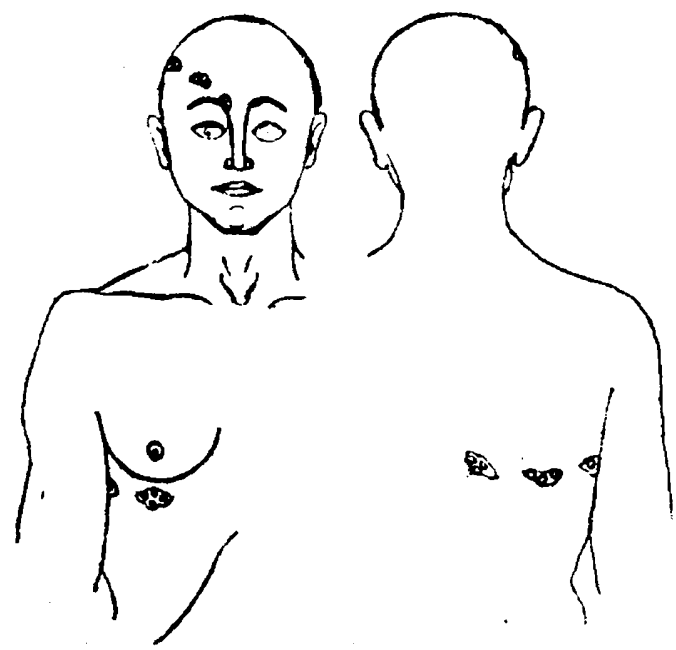

Fig. 1 (Case 1),-Location of zoster outbreak.

\section{REPORT OF CASES}

CASE 1.-Annie I., an Irish housemaid, aged 50, was admitted, Nov. 8, 1920, to the women's medical ward of the Presbyterian Hospital. Her mentality was confused and her speech slurred. There was palsy of each superior rectus and elevator of the upper lid. For several days she was delirious and stuporous by turns, and it was thought she had a bulbar lethargic encephalitis. A nose and throat examination disclosed only the fact that the right frontal sinus did not transmit light as well as the left. Laboratory findings gave no special positive results. The Wassermann reaction was negative, Nov. 11,

2. Mobley, C. A.: A Case of Asymmetrical, Bilateral Herpes Zoster, J. A. M. A. 59:879 (Sept. 14) 1912 .

3. Hutchinson, J.: London Hospital Lectures, 1866, p. 68.

4. Barber, H. W.: Lancet 2:1136 (Dec. 20) 1919.

5. Bradshaw, T. R.: Lancet 2:851 (Oct. 13) 1894. 
1920, and Feb. 1, 1921. The urine showed at times a trace of albumin and numerous pus cells. Smears and cultures made from the spinal fluid were uniformly negative. The cell count was 4 per cubic millimeter. The blood showed a leukocytosis never greater than 12,000 , and, as the disease progressed, an anemia of moderate degree.

By Jan. 1, 1921, the patient was slowly improving. She had been taking solution of potassium arsenite (Fowler's solution) since Nov. 28, 1920. Jan. 6,1921 , an eruption was noticed over the posterior aspect of the right thorax. January 8, one of us first saw the case. Commencing over the scapula in the area ascribed to the sixth thoracic segment, and continuing around to the nipple line, were four or five scattered groups of vesicles on inflamed basesa typical thoracic zoster. At the same time, an outbreak of the same disease was noted on the right side of the patient's forehead. Three patches were present, the most nearly median at the inner end of the eyebrow, the next over the frontal boss, and the third on the temple near the hairline. In both situations the eruption was unmistakable. The right axillary lymph nodes were

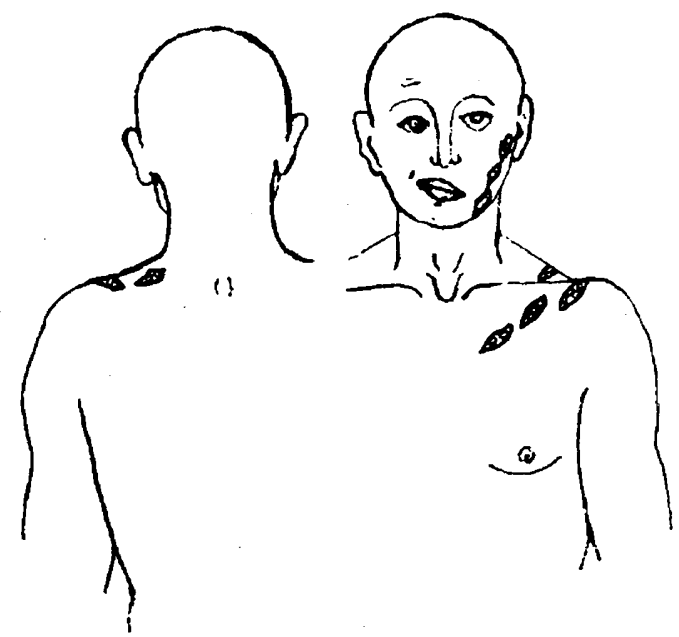

Fig. 2 (Case 2).-Herpes zoster with facial palsy.

at that time enlarged, though on admission they were not palpable. Owing to the patient's drowsy condition, no history of pain was obtained. When she was transferred to the Philadelphia Hospital, February 14, the eruption had virtually disappeared.

The administration of arsenic in this case may have been an etiologic factor, it being well known that numerous cases of herpes zoster have occurred in patients taking that drug. This is said to be especially true in recurrent cases of the disease.

A far more frequent variation in this disease is a motor palsy accompanying the eruption of zoster. Even this complication is not commonly encountered, and some dermatologists of wide experience have not encountered such a case. Greenough ${ }^{8}$ saw 255 cases of zoster

6. Greenough, F. B.: Boston M. \& S. J. 121:339 (Oct. 3) 1889. 
in sixteen years. But two of this number showed an associated palsy. Hunt collected 158 cases of paralyses of various kinds in herpes zoster. Of these, eighty were of the facial nerve, with, in each instance, an eruption confined to the cephalic extremity. There were auditory nerve complications in thirty of them, varying from a simple diminution of hearing to severe symptoms of Ménière's syndrome. According to Weber," "Doucet considered that the paralyses were generally of peripheral origin and incomplete; the paralyzed parts were mostly in the neighborhood of the distribution of the herpes zoster; only rarely were they at a distance."

CASE 2.-J. H., a white man, aged 26 , a wireman, came to the skin dispensary of the Jefferson Hospital, Jan. 28, 1921. There was an eruption of five days' duration on the left side of the face, and in the supraclavicular, infraclavicular and suprascapular regions of the same side. On both the face and the shoulder, the outbreak showed a typical zoster eruption and the diagnosis was not questioned by the various members of the staff who saw the case. In addition, there existed a left facial palsy which, the patient said, had appeared at the same time as the eruption. There was no disturbance of hearing, or dizziness; no hiccuping or nausea. Some abnormality of the sense of taste had been noted, but no test was made by us. The patches on the face were located in front of the ear and lower, over the ramus and body of the mandible in the area supplied by the third cervical root. The eruption over the clavicle was entirely in the area innervated by the fourth cervical root. No outbreak was found on the auricle or in the canal.

The case was referred to the nervous dispensary for treatment of the Bell's palsy, but the patient did not go there and was lost sight of until all symptoms had disappeared. He later reported that the eruption cleared up in about three weeks, and that the paralysis had totally disappeared in six weeks.

\section{CONCLUSION}

In those cases of herpes zoster associated with facial palsy, the geniculate ganglion has uniformly been found inflamed when examined. The sensory ganglions affected in this case were the third and fourth cervical. While it is customary for only one ganglion to be involved, Hunt $^{8}$ says, "It is probable that two ganglions are occasionally affected together. From clinical observation this seem particularly liable to occur with the second, third and fourth cervical."

In Hunt's table of types of eruption found in the eighty cases associated with facial palsy, only one was of the combined facial and occipito-collaris distribution. As our second case appears to be of that type, it would seem of sufficient rarity to justify reporting.

2039 Chestnut Street-2022 Spruce Street.

7. Weber, F. P.: Brit. J. Dermat. 27:408, 1915.

8. Hunt, J. R.: Am. J. M. Sc. 136:226. 